\title{
An inhibitor of the acetyltransferases CBP/p300 exerts antineoplastic effects on gastrointestinal stromal tumor cells
}

\author{
MENG-LI GU ${ }^{1}$, YA-MEI WANG ${ }^{1}$, XIN-XIN ZHOU ${ }^{1}$, HANG-PING YAO $^{2}$, \\ SONG ZHENG $^{3}, \mathrm{ZUN}^{\mathrm{XIANG}}{ }^{1}$ and FENG JI ${ }^{1}$

\begin{abstract}
${ }^{1}$ Department of Gastroenterology, The First Affiliated Hospital of Medical College of Zhejiang University; ${ }^{2}$ State Key Laboratory for Diagnosis and Treatment of Infectious Diseases, The First Affiliated Hospital, College of Medicine, Zhejiang University, Hangzhou, Zhejiang 310003; ${ }^{3}$ Department of Oncology, Hangzhou Cancer Hospital, Hangzhou First People's Hospital, Hangzhou, Zhejiang 310006, P.R. China
\end{abstract}

Received April 5, 2016; Accepted August 16, 2016

DOI: $10.3892 / o r .2016 .5080$

\begin{abstract}
Gastrointestinal stromal tumors (GISTs) are the most common mesenchymal neoplasm featured by activated mutations of KIT and PDGFRA. Although overall survival rates have greatly improved by the development of receptor tyrosine kinase inhibitors, most patients ultimately acquire resistance due to secondary mutations of KIT or PDGFRA. Inhibition of the histone acetyltransferases (HATs) CREB-binding protein (CBP) and p300 results in antineoplastic effects in various cancers. To determine whether $\mathrm{CBP} / \mathrm{p} 300$ can serve as an antineoplastic target for GISTs, specific short interfering RNA sequences and the selective HAT inhibitor C646 were administered to GIST882 cells. Cell viability, apoptosis and the cell cycle were analysed using the Cell Counting Kit-8, a caspase-3/7 activity assay or Annexin V-fluorescein isothiocyanate/propidium iodide (PI) staining and PI staining. Gene and protein expression levels were measured by quantitative real-time polymerase chain reaction and western blotting, respectively. Transcriptional blockage of $C B P$, rather than $p 300$, resulted in suppression of cell proliferation. Interestingly, both CBP and p300 depletion enhanced caspase-3/7 activity. A lack of CBP and p300 caused ETS translocation variant 1 (ETV1) downregulation and KIT inhibition in GIST cells. Nevertheless, the absence of CBP, not p300, leads to extracellular signal-regulated kinase $1 / 2$ inactivation and c-Jun $\mathrm{NH}_{2}$-terminal kinase activation, suggesting a more crucial role for CBP than p300 in cell proliferation and survival. Furthermore, proliferation of GIST cells was reduced by administration of C646, a selective HAT inhibitor for CBP/p300. Apoptosis induction and cell cycle
\end{abstract}

Correspondence to: Professor Feng Ji, Department of Gastroenterology, The First Affiliated Hospital of Medical College of Zhejiang University, 79 Qingchun Road, Hangzhou, Zhejiang 310003, P.R. China

E-mail: jifeng1126@sina.com

Key words: gastrointestinal stromal tumor, CREB-binding protein, p300, acetylation, C646, antineoplastic, signaling pathway arrest were detected after exposure to C646, indicating that its antitumor activities were supported by its antiproliferative and proapoptotic effects. Additionally, C646 treatment attenuated ETV1 protein expression and inactivated KIT-dependent pathways. Taken together, the present study suggests that $\mathrm{CBP} / \mathrm{p} 300$ may serve as novel antineoplastic targets and that use of the selective HAT inhibitor C646 is a promising antitumor strategy for GISTs.

\section{Introduction}

Gastrointestinal stromal tumors (GISTs), the most common mesenchymal neoplasms of the gastrointestinal tract (1), are characterized by gain-of-function mutations of the KIT or PDGFRA genes $(2,3)$. They most likely originate from the interstitial cells of Cajal (ICC) or Cajal-like precursor cells whose immunohistochemical marker is CD117 $(4,5)$. In recent years, the receptor tyrosine kinase (RTK) inhibitor imatinib mesylate (Gleevec; Novartis Pharmaceuticals Corp., East Hanover, NJ, USA), which targets the KIT and PDGFRA oncoproteins, has frequently been used to treat patients with advanced GISTs or has been used as an adjuvant agent (6). Although up to $70 \%$ of GIST patients respond to imatinib well at first, $\sim 15 \%$ of patients may develop primary resistance, and most responding patients will eventually develop secondary resistance and have disease progression (7). Thus, novel therapeutic targets and effective antineoplastic strategies are still needed.

Primary resistance is mainly caused by KIT exon 9 mutations and the lack of activating KIT mutations, resulting in resistance to imatinib. The PDGFRA mutation $\mathrm{D} 842 \mathrm{~V}$ on exon 18 also contributes to primary resistance in GISTs (8). Acquired secondary mutations in the kinase domains of KIT or PDGFRA will lead to the development of imatinib resistance in most patients (9). Moreover, it has been reported that stem cell factor (SCF), a KIT ligand, may contribute to the acquired imatinib resistance (10). Although an increasing number of new-generation RTK inhibitors, such as sunitinib, nilotinib, vatalanib and masatinib, have demonstrated their antineoplastic activities in GISTs (11), the therapeutic effect varies depending on the pattern of genetic alterations 
Therefore, it is imperative that novel molecular targets and selective agents be developed and investigated to revolutionize antitumor strategies.

CREB-binding protein (CBP) and p300 (collectively referred to as $\mathrm{CBP} / \mathrm{p} 300$ ) are transcriptional co-activators that integrate and maintain various gene regulator pathways and protein acetylation events with intrinsic histone acetyltransferase (HAT) activity (12). Over the last few years, their biological and pathological functions have been under extensive investigation. $\mathrm{CBP} / \mathrm{p} 300$ play pivotal roles in differentiation, apoptosis and the cell cycle $(13,14)$. However, there is a distinct relationship between $\mathrm{CBP} / \mathrm{p} 300$ activity and tumorigenesis and malignancy. $\mathrm{CBP} / \mathrm{p} 300$ inactivation will not only inhibit the growth of prostate cancer cells and melanoma cells $(15,16)$ but will also induce apoptosis and cell cycle arrest in leukaemia cells (17). Interestingly, it has been illustrated that the co-activators CBP and p300 interact with an oncoprotein ETS translocation variant 1 (ETV1) (18), a distinctive transcription factor that is overexpressed in most prostate cancers (19). In addition, p300 directly acetylates ETV1 and thereby enhances its stability, DNA-binding capacity, and transcriptional activity in vitro (20). Recent studies have demonstrated that ETV1 is a specific survival factor that cooperates with KIT in GISTs, and our previous findings showed that ETV1 was highly upregulated within tumor tissues in conjunction with KIT expression $(21,22)$. Therefore, CBP/p300 may play a vital role in tumorigenesis and progression of GISTs by regulating the functions of ETV1 and KIT-dependent pathways, serving as promising targets for antineoplastic therapy.

Recently, a small molecule inhibitor targeting CBP/p300, C646, has gained much attention for its anticancer potential. C646 administration inhibits histone acetylation and cell growth with relatively high selectivity and potency, suggesting its application as a prospective anticancer agent (23). Although the antitumor activity of $\mathrm{C} 646$ has been investigated in other tumors $(15,17)$, its effects on GISTs have not yet been assessed. Here, we explored the therapeutic relevance of $\mathrm{CBP} / \mathrm{p} 300$ inhibition in GISTs and further investigated the possible mechanisms underlying its antineoplastic activity in vitro.

\section{Materials and methods}

Cell culture and reagents. The GIST882 cell line carrying the homozygous KIT exon 13 K642E (KIT-exon13) mutation was a generous gift from Dr Jonathan Fletcher (Dana-Farber Cancer Institute, Boston, MA, USA). GIST882 cells were grown in RPMI-1640 medium (Corning Inc., Corning, NY, USA) with $15 \%$ fetal bovine serum (FBS), $100 \mathrm{U} / \mathrm{ml}$ penicillin and $0.1 \mathrm{mg} / \mathrm{ml}$ streptomycin. The GIST cells were maintained in a humidified incubator at $37^{\circ} \mathrm{C}$ in a $5 \% \mathrm{CO}_{2}$ atmosphere. The CBP/p300 inhibitor, C646, was purchased from Selleck Chemicals LLC (Shanghai, China).

Transfection of short interfering RNA (siRNA). To determine the role of $\mathrm{CBP} / \mathrm{p} 300$ in GIST proliferation and apoptosis, GIST882 cells were cultured in 6- and 96-well plates until 70-80\% confluence, respectively. siRNA transfections were performed with Lipofectamine RNAiMAX reagent (Invitrogen
Life Technologies, Carlsbad, CA, USA) in antibiotics-free medium according to the manufacturer's instructions. GIST882 cells were transfected with $10 \mathrm{nmol} / 1 \mathrm{siRNA}$. The control siRNA and siRNA against CBP and p300 were purchased from Santa Cruz Biotechnology, Inc. (Dallas, Texas, USA).

Cell proliferation assay. GIST 882 cells $\left(1.5 \times 10^{4} /\right.$ well) were seeded in 96-well plates and further cultured for $48 \mathrm{~h}$ before C646 and siRNA were added. After administration of C646 (for 24 and $48 \mathrm{~h}$ ) or transfection with siRNA (for 24, 48 and $72 \mathrm{~h}$ ), $10 \mu 1$ of Cell Counting Kit-8 (CCK-8; Dojindo Laboratories, Kumamoto, Japan) solution was added to each well, followed by incubation for $2 \mathrm{~h}$ at $37^{\circ} \mathrm{C}$. The optical density (OD) was measured at $450 \mathrm{~nm}$ with a microplate reader (Bio-Rad Laboratories, Inc., Hercules, CA, USA). The mean OD values from 4-wells for each treatment were used as the index of cell viability. All experimental points were replicated in three plates. Cell viability was calculated using the following formula: $O D$ value of each set/OD value of control group (DMSO control and blank control, respectively) x 100.

Caspase activity assay. GIST882 cells $\left(1.5 \times 10^{4} /\right.$ well) were cultured in a 96-well plate for $48 \mathrm{~h}$ before being transfected with siRNA or treated with C646. After transfection with siRNA (for 24, 48 and $72 \mathrm{~h}$ ) or administration of C646 (for 24 and $48 \mathrm{~h}$ ), caspase-Glo 3/7 reagent (Promega, Madison, WI, USA) was added to each well at a ratio of 1:1 following the manufacturer's instructions. The luminescence intensity of each sample was measured in a plate-reading luminometer (Promega). Caspase activity was expressed as a percentage of the control level [blank and dimethyl sulfoxide (DMSO) controls, respectively]. Luminescence intensity was measured in quadruplicate, and all experimental points were replicated in three plates.

Cell apoptosis assay. Apoptosis induction was detected using an Annexin V-fluorescein isothiocyanate (FITC)/propidium iodide (PI) apoptosis assay kit (Invitrogen Life Technologies). GIST 882 cells $\left(7 \times 10^{5} /\right.$ well) were plated on 6 -well plates and further cultured for $48 \mathrm{~h}$ before being treated with C646. After incubation for 24,48 or $72 \mathrm{~h}$, the cells were harvested by trypsin without EDTA and centrifuged at $200 \mathrm{x}$ g for $5 \mathrm{~min}$. The cell pellets were resuspended in $100 \mu 1$ of $1 \mathrm{X}$ binding buffer. Next, $5 \mu \mathrm{l}$ of Annexin V-FITC and $1 \mu \mathrm{l}$ of PI were added and mixed well. After incubation for $15 \mathrm{~min}$ in the dark, $400 \mu \mathrm{l}$ of $1 \mathrm{X}$ binding buffer was added to each sample. The stained cells were evaluated by flow cytometry (NovoCyte; ACEA Biosciences, Inc., San Diego, CA, USA), and the data were analysed using FlowJo 7.6.2 software (Tree Star, Inc., Ashland, OR, USA). All experimental sets were conducted in triplicate.

Cell cycle assay. Cell cycle analysis was performed using a Cell Cycle kit purchased from Multi Sciences (Lianke) Biotech Co., Ltd. (Hangzhou, China). GIST882 cells (7x10 $/$ well) were seeded in 6-well plates and further cultured for $48 \mathrm{~h}$ before being treated with C646. After administration of C646 for 24,48 or $72 \mathrm{~h}$, the cells were trypsinized and collected by centrifugation at $200 \mathrm{x}$ g for $5 \mathrm{~min}$. The cells were then fixed with $75 \%$ ethanol at $-20^{\circ} \mathrm{C}$ overnight and rehydrated with 
ice-cold PBS for 15 min before being stained with $1 \mathrm{ml}$ of DNA staining solution. The stained cells were then evaluated by flow cytometry as described above, and the data were analysed using ModFit LT V3.3.11 software (Verity Software House, Inc., Topsham, ME, USA). All experimental sets were conducted in triplicate.

Quantitative real-time polymerase chain reaction $(P C R)$. According to the transfection protocol, GIST882 cells were divided into four groups: blank, negative control (NC), sip300 and siCBP. The total RNA of each sample was extracted using TRIzol reagent (Invitrogen Life Technologies) following the manufacturer's instructions. Total RNA $(2 \mu \mathrm{g})$ was reversetranscribed using the PrimeScript ${ }^{\mathrm{TM}}$ RT reagent kit with gDNA Eraser (Takara Biotechnology, Co., Ltd., Dalian, China). DNA products were amplified with $\mathrm{SYBR}^{\circledR}$ Premix Ex $\mathrm{Taq}^{\mathrm{TM}}$ (Tli RNaseH Plus) (Takara Biotechnology, Co., Ltd.). The primer sequences were as follows: forward, 5'-CCTGAG TAGGGGCAACAAGA-3' and reverse, 5'-GTGTCTCCACA TGGTGCTTG-3' for human p300; forward, 5'-CTGCACAC GACATGACT-3' and reverse, 5'-GAAGTGGCATTCTG TTG-3' for human $C B P$; and forward, 5'-AGAAGGCTGG GGCTCATTTG-3' and reverse, 5'-AGGGGCCATCCACA GTCTTC-3' for human glyceraldehyde 3-phosphate dehydrogenase $(G A P D H)$. Real-time PCR was performed using a 7500 Real-Time PCR system (Applied Biosystems, Foster City, CA, USA). The thermocycling conditions were $10 \mathrm{~min}$ at $95^{\circ} \mathrm{C}$ as the initial denaturation step, followed by 40 cycles at $95^{\circ} \mathrm{C}$ for $30 \mathrm{sec}$ and $60^{\circ} \mathrm{C}$ for $34 \mathrm{sec}$. Gene expression levels were measured using the threshold cycle $(\mathrm{Ct})$ value, and relative fold-expression changes were normalized to GAPDH amplification. The $2^{-\triangle \Delta C T}$ method was used to measure the relative changes in gene expression.

Western blotting. Total proteins were harvested from GIST882 cells using cell lysis buffer (Cell Signaling Technology, Inc., Beverly, MA, USA) according to the manufacturer's instructions. Equal amounts of protein were applied to $8-12 \%$ gels and were subjected to SDS-PAGE. The samples were then transferred to polyvinylidene difluoride (PVDF) membranes using a semidry transfer system (Bio-Rad Laboratories, Inc.). Membranes were blocked for $2 \mathrm{~h}$ at room temperature with $5 \%$ dry milk in Tris-buffered saline with Tween ${ }^{\circledR}-20$ (TBST) and were incubated overnight at $4{ }^{\circ} \mathrm{C}$ with specific polyclonal rabbit anti-human antibodies corresponding to c-KIT $(1: 2,000)$, phospho-c-KIT (Tyr703) $(1: 2,000), \mathrm{CBP}$ $(1: 1,000)$, extracellular signal-regulated kinase $($ ERK $) 1 / 2$ (1:2,000), phospho-ERK1/2 (Thr202/Tyr204 for ERK1 and Thr183/Tyr185 for ERK2 (1:2,000), c-Jun $\mathrm{NH}_{2}$-terminal kinase (JNK) $(1: 1,000)$, phospho-JNK (Thr183/Tyr185) $(1: 1,000)$, Bax $(1: 2,000)$, Bcl-2 (1:1,000), and GAPDH $(1: 5,000)$ (Cell Signaling Technology, Inc.), along with rabbit anti-human antibodies against p300 (1:1,000) (Santa Cruz Biotechnology, Inc.) and ETV1 (1:1,000) (Abcam, Cambridge, UK). Membranes were washed with TBST and incubated with 1:5,000 anti-rabbit horseradish peroxidase (HRP)-conjugated secondary antibody (Abcam) for $1 \mathrm{~h}$ at room temperature and then washed again. Immune complexes were detected with an enhanced chemiluminescence reagent (Millipore, Billerica MA, USA), acquired in the linear range of the scanner and analysed using Quantity One software (Bio-Rad Laboratories, Inc.).

Statistical analysis. Results are expressed as the means \pm standard deviations. Multiple comparisons between groups were performed using Tukey's range test. Statistically significant differences are indicated by $\mathrm{P}<0.05$. All analyses were performed using GraphPad Prism 6 (GraphPad Software, Inc., San Diego, CA, USA).

\section{Results}

CBP inhibition suppresses GIST882 cell proliferation. To determine whether $\mathrm{CBP} / \mathrm{p} 300$ can serve as antineoplastic targets for GISTs, specific siRNAs against $C B P$ and $p 300$ were transfected into GIST882 cells. As shown in Fig. 1A and B, siRNA transfection for $72 \mathrm{~h}$ attenuated CBP and p300 protein expression, consistent with their decreased mRNA expression levels (Fig. 1C and D). CBP downregulation led to decreased cell viability, whereas a similar effect was not observed upon p300 depletion in GIST882 cells (Fig. 1E), indicating that CBP and $\mathrm{p} 300$ potentially play different roles in GIST proliferation in spite of their high homology.

CBP/p300 downregulation enhances caspase-3/7 activity in GIST882 cells. In the present study, caspase-3/7 activity was measured to evaluate apoptosis induction following $\mathrm{CBP} / \mathrm{p} 300$ downregulation. As shown in Fig. 1F, consistent with the antiproliferative effects induced by $C B P$ silencing, caspase-3/7 activity in GIST882 cells was markedly enhanced 3.5-fold compared with the negative control after transfection for $72 \mathrm{~h}(\mathrm{P}<0.01)$. Notably, inhibition of $p 300$ by siRNA also increased caspase-3/7 activity 2.2-fold, which was much higher than that in the negative control group after transfection for $72 \mathrm{~h}(\mathrm{P}<0.01)$.

CBP/p300 silencing results in inhibition of ETV1 and KIT-dependent pathways and activation of apoptotic pathways. To elucidate the molecular mechanisms involved in the antineoplastic effects on GIST882 cells, we detected ETV1 protein levels and KIT-dependent pathway regulation following siRNA transfection for $72 \mathrm{~h}$. As shown in Fig. 2, both $C B P$ and $p 300$ inhibition caused considerable ETV1 degradation compared with the negative control. Phosphorylation of KIT decreased considerably as CBP and p300 were downregulated. In addition, silencing of $C B P$, rather than $p 300$, strongly attenuated the phosphorylation of ERK1/2 and activated JNK in GIST882 cells; the total ERK1/2 and JNK expression levels scarcely changed within the groups. In this study, the expression of several mitochondrial-related apoptotic proteins, including Bcl-2, Bcl-xL and Bax, was also evaluated to shed light on the possible mechanisms of apoptosis induced by $\mathrm{CBP} / \mathrm{p} 300$ inhibition. Our results demonstrated that the expression of anti-apoptotic Bcl-2 and Bcl-xL decreased after siRNA transfection, whereas pro-apoptotic Bax expression increased considerably.

C646 inhibits cell proliferation and activates caspase-3/7 in GIST882 cells. As mentioned above, CBP/p300 downregulation exerted antiproliferative effects on GIST882 cells via inhibition 
A

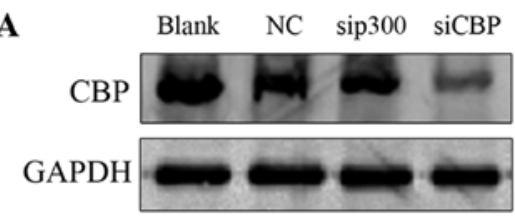

C

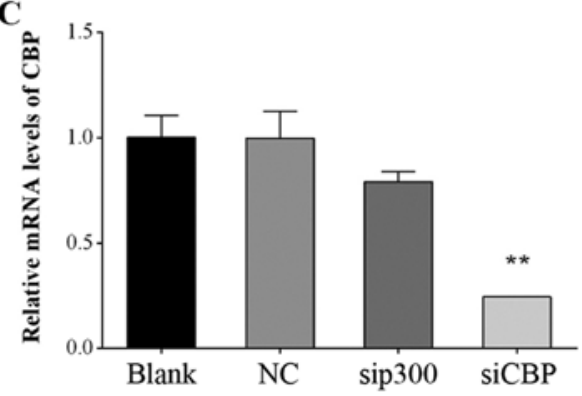

$\mathbf{E}$

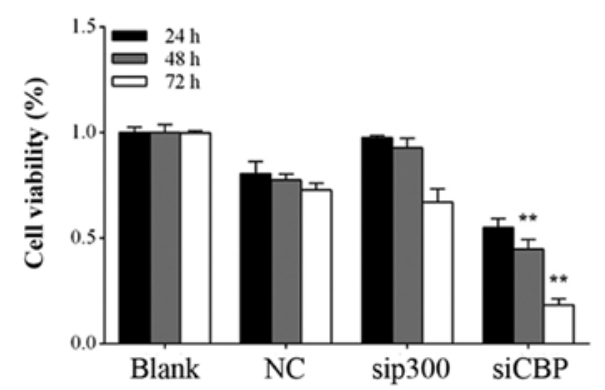

B

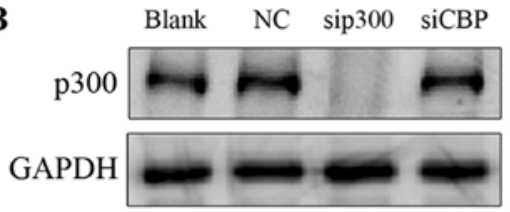

D

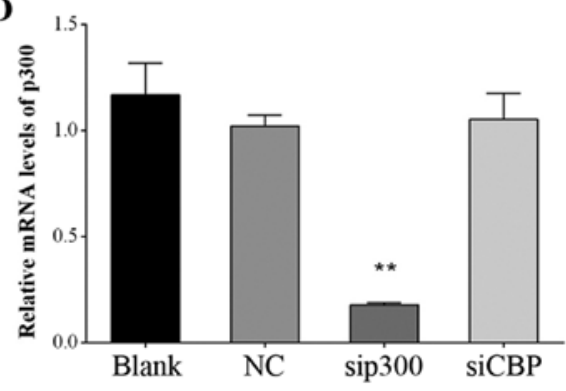

F

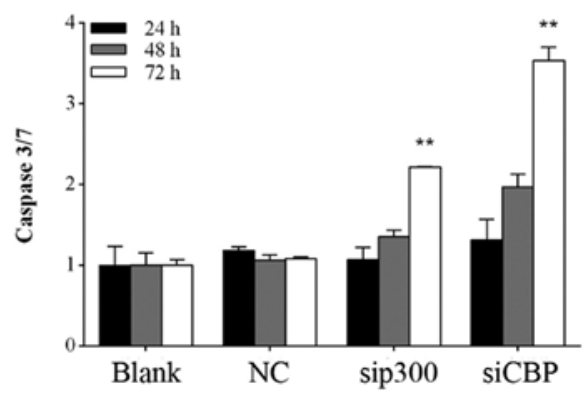

Figure 1. $C B P / p 300$ silencing and their discrepant effects on proliferation and apoptosis in a GIST cell line. GIST882 cells were transfected with siRNAs against $C B P$ and $p 300$. (A and B) Western blotting was performed after transfection for $72 \mathrm{~h}$ to validate the efficiency of $C B P$ and $p 300$ silencing. (C and D) Quantitative real-time PCR was performed to evaluate the mRNA levels of $C B P$ and $p 300$ in GIST882 cells after transfection for $72 \mathrm{~h}$ ("* $\mathrm{P}<0.01$ compared with the negative control group). (E) Cell proliferation was assessed using a CCK-8 assay after transfection for 24,48 and $72 \mathrm{~h}$, respectively ("* $\mathrm{P}<0.01 \mathrm{vs.}$. the negative control group at each time-point). (F) Caspase-3/7 activity was measured after transfection for 24,48 and $72 \mathrm{~h}$, respectively (** $\mathrm{P}<0.01$ vs. the negative control group transfected for $72 \mathrm{~h}$ ). CBP, CREB-binding protein; GIST, gastrointestinal stromal tumor; NC, negative control; CCK-8, Cell Counting Kit-8.

of cell proliferation and caspase-3/7 activation. Therefore, we next investigated whether C646, a selective CBP/p300 inhibitor, was able to exert similar effects. Its potential antineoplastic activity was validated by treating GIST882 cells with an increasing concentration of C646 (5-15 $\mu \mathrm{mol} / \mathrm{l})$ for 24 and $48 \mathrm{~h}$, respectively. Moreover, imatinib $(500 \mathrm{nmol} / \mathrm{l})$ alone or in combination with C646 at the same doses (5-15 $\mu \mathrm{mol} / \mathrm{l})$ were used to assess the possible additive effect. As shown in Fig. 3A, C646 administration had strong inhibitory effects on cell proliferation in the GIST822 cells. The cell viability of GIST882 cells significantly decreased after treatment with imatinib combined with C646 (15 $\mu \mathrm{mol} / \mathrm{l})$ for $48 \mathrm{~h}$ compared with the group treated with $15 \mu \mathrm{mol} / 1 \mathrm{C} 646$ alone $(\mathrm{P}<0.01)$. To detect caspase-3/7 activity, C646 (1-15 $\mu \mathrm{mol} / \mathrm{l})$ alone or in combination with imatinib (500 nmol/l) was administered to GIST cells for 24 and $48 \mathrm{~h}$, respectively. As shown in Fig. 3B, exposure to $15 \mu \mathrm{mol} / 1$ of $\mathrm{C} 646$ led to a 4.1-fold upregulation in caspase-3/7 activity after $48 \mathrm{~h}$ compared with DMSO control group $(\mathrm{P}<0.01)$. Administration of imatinib (500 nmol/l) alone for $48 \mathrm{~h}$ resulted in a 2.5-fold increase in caspase-3/7 activity compared with DMSO control group $(\mathrm{P}<0.01)$. In the combination studies, caspase-3/7 activity significantly increased after treatment with imatinib combined with C646 $(15 \mu \mathrm{mol} / \mathrm{l})$ for $48 \mathrm{~h}$ compared with the group treated with $15 \mu \mathrm{mol} / 1 \mathrm{C} 646$ alone $(\mathrm{P}<0.01)$.
C646 exerts its antineoplastic effect via apoptosis induction and cell cycle arrest in GIST882 cells. To further assess the apoptosis induced by C646, Annexin V-FITC/PI staining and flow cytometry were performed. C646 administration induced significant apoptosis in GIST cells compared with DMSO control group (Fig. 4A). As shown in Fig. 4B, apoptotic cell death was induced in a dose-dependent manner, and $15 \mu \mathrm{mol} / 1 \mathrm{C} 646$ caused significant apoptosis in GIST cells compared with DMSO group $(\mathrm{P}<0.01)$. In addition, the apoptotic rate increased accordingly over time in GIST882 cells exposed to $15 \mu \mathrm{mol} / 1 \mathrm{C} 646$ (Fig. 4C). The effect of C646 on the cell cycle was examined via PI staining and flow cytometry. Our results indicated that C646 treatment led to an increase in GIST cells in the G1-phase, whereas the S-phase population declined considerably (Fig. 4D). Notably, C646 (15 $\mu \mathrm{mol} / \mathrm{l})$ immediately induced cell cycle arrest at the G1-phase in GIST882 cells within $24 \mathrm{~h}$; this inhibitory effect did not follow a dose- or time-dependent pattern (Fig. 4E and F).

C646 attenuates ETV1 expression and inactivates KIT-dependent pathways. To address the molecular mechanisms underlying the antineoplastic effects induced by C646 in GIST882 cells, the expression levels of ETV1 and functional changes in the KIT pathway were explored. The GIST cells 


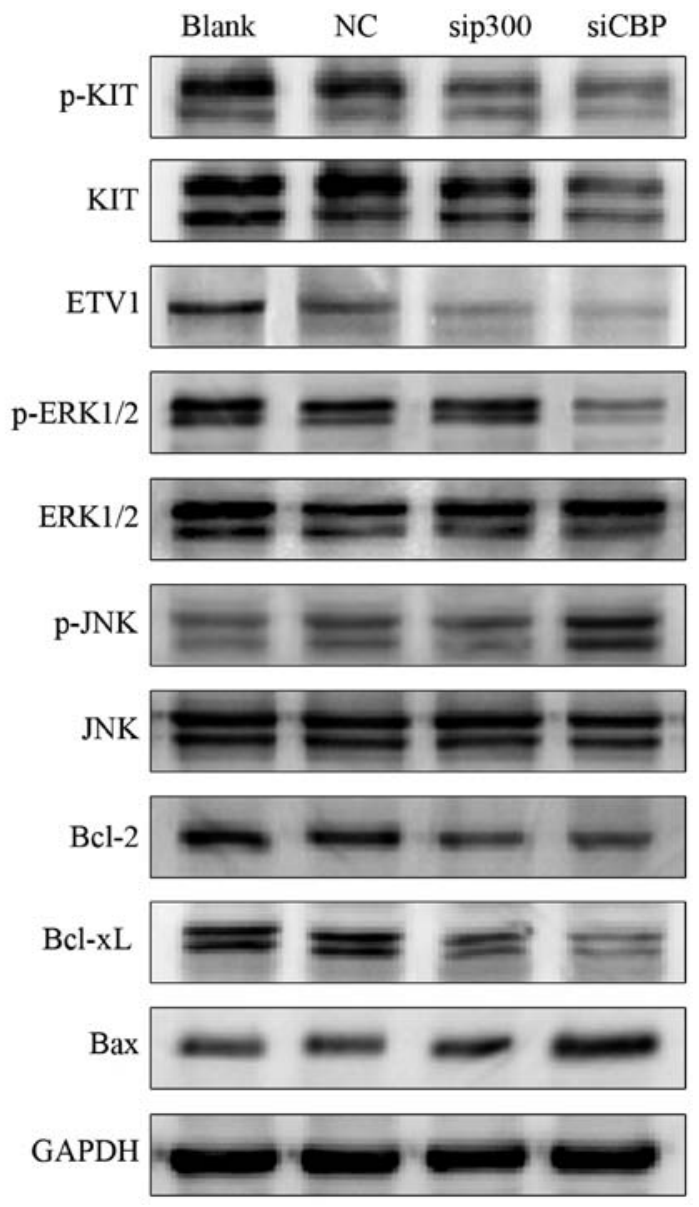

Figure 2. $C B P / p 300$ inhibition causes ETV1 inhibition, KIT-dependent pathway inactivation and apoptotic pathway activation. GIST882 cells were transfected with siRNAs targeting $C B P$ and $p 300$ for $72 \mathrm{~h}$. Western blotting was performed to detect the expression levels of ETV1, KIT-dependent signalling pathway-related proteins and apoptotic pathway-related proteins. GAPDH was used as a reference. CBP, CREB-binding protein; ETV1, ETS translocation variant 1; GIST, gastrointestinal stromal tumor; siRNA, short interfering RNA; GAPDH, glyceraldehyde 3-phosphate dehydrogenase.

were treated with C646 (5-20 $\mu \mathrm{mol} / \mathrm{l})$ and imatinib (500 nmol/l) alone and in combination with C646 $(15 \mu \mathrm{mol} / \mathrm{l})$ and were further incubated for $24 \mathrm{~h}$. As shown in Fig. 5, C646 administration strongly decreased ETV1 expression in a dose-dependent manner. Considerable inhibition of KIT phosphorylation was observed following C646 treatment. Moreover, the phosphorylation levels of Akt and ERK1/2 were attenuated accordingly after exposure of the cells to C646 for $24 \mathrm{~h}$. In contrast, C646 had little effect on the expression levels of total Akt and ERK1/2. In the combination study, synergistic inhibitory effects on KIT and ERK1/2 activation were observed in GIST882 cells after treatment with comparatively low concentrations of imatinib $(500 \mathrm{nmol} / \mathrm{l})$ and C646 $(15 \mu \mathrm{mol} / \mathrm{l})$. Taken together, C646 may exert its antineoplastic effects through inhibition of ETV1 expression and inactivation of the KIT-dependent pathway, leading to suppressed phosphorylation of Akt and ERK1/2.

\section{Discussion}

Recent advances in the knowledge of GIST pathogenesis have contributed to the rapid developments of therapeutic agents
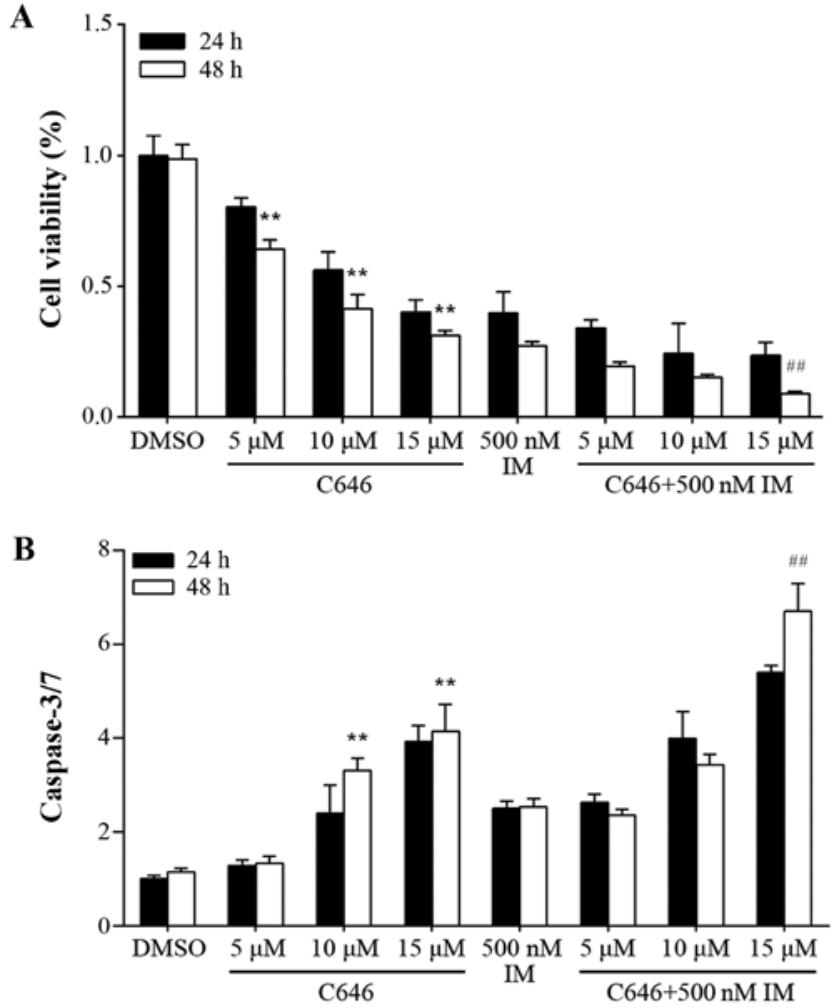

Figure 3. The CBP/p300 inhibitor C646 induces suppression of cell proliferation and apoptosis. GIST882 cells were treated with C646 at doses ranging from 5 to $15 \mu \mathrm{mol} / 1$ for 24 or $48 \mathrm{~h}$. Imatinib ( $500 \mathrm{nmol} / \mathrm{l})$ alone or in combination with $\mathrm{C} 646$ at the same doses $(5-15 \mu \mathrm{mol} / \mathrm{l})$ were used to evaluate the possible synergistic effect. DMSO was used as the vehicle control. (A) Cell proliferation was measured using a CCK- 8 assay ( ${ }^{* *} \mathrm{P}<0.01$ vs. DMSO group treated for $48 \mathrm{~h},{ }^{\# \#} \mathrm{P}<0.01 \mathrm{vs}$. the group treated with $15 \mu \mathrm{mol} / 1 \mathrm{C} 646$ for $48 \mathrm{~h}$ ). (B) Cellular apoptosis was assessed based on caspase-3/7 activity $\left({ }^{* *} \mathrm{P}<0.01\right.$ vs. DMSO group treated for $48 \mathrm{~h},{ }^{\# \#} \mathrm{P}<0.01$ vs. the group treated with $15 \mu \mathrm{mol} / 1$ C646 for 48 h). CBP, CREB-binding protein; GIST, gastrointestinal stromal tumor; DMSO, dimethyl sulfoxide; CCK-8, Cell Counting Kit-8.

targeting abnormalities in KIT and PDGFRA. Although the advent of potent RTK inhibitors, such as imatinib and sunitinib, has greatly improved median overall survival in inoperable and metastatic cases (24-26), most patients eventually develop resistance due to various resistance mechanisms $(27,28)$, representing a clinical challenge to antitumor therapy. As secondary mutations have appeared in the majority of the patients who develop resistance (9), present antineoplastic strategies are aimed at improving the efficiency and selectivity of the anticancer therapy in spite of these mutations. Based on this goal, posttranslational modifications involving oncology and therapy have been intensively studied in GISTs over the past few decades. It has been suggested that microRNA-221/222 may serve as a new therapeutic strategy for treating TKI-resistant GIST (29). Here, we explore the functions of the HAT proteins CBP and p300, which are involved in GIST tumorigenesis.

Being a part of the vital molecules in posttranslational modifications, the acetyltransferases $\mathrm{CBP} / \mathrm{p} 300$ play crucial roles in oncogenesis and progression. $\mathrm{CBP} / \mathrm{p} 300$ are known to have tumor-promoting effects as they have been shown to accelerate the progression of colon and prostate cancers $(30,31)$. However, mutations of the $C B P$ and $p 300$ genes or dysfunction of the proteins will promote cell proliferation and consequently increase the incidence of haematological malignancies, 
A

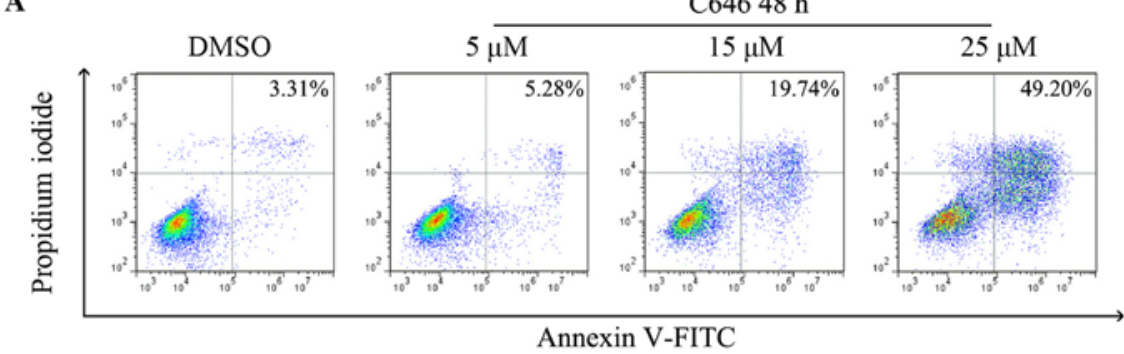

B

$\mathrm{C}$

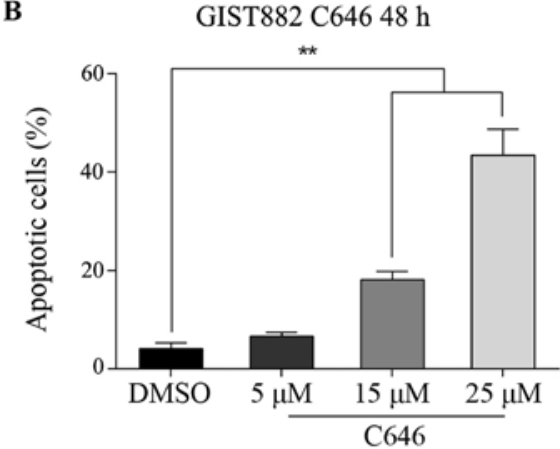

CIST882 C646 $15 \mu \mathrm{M}$

D
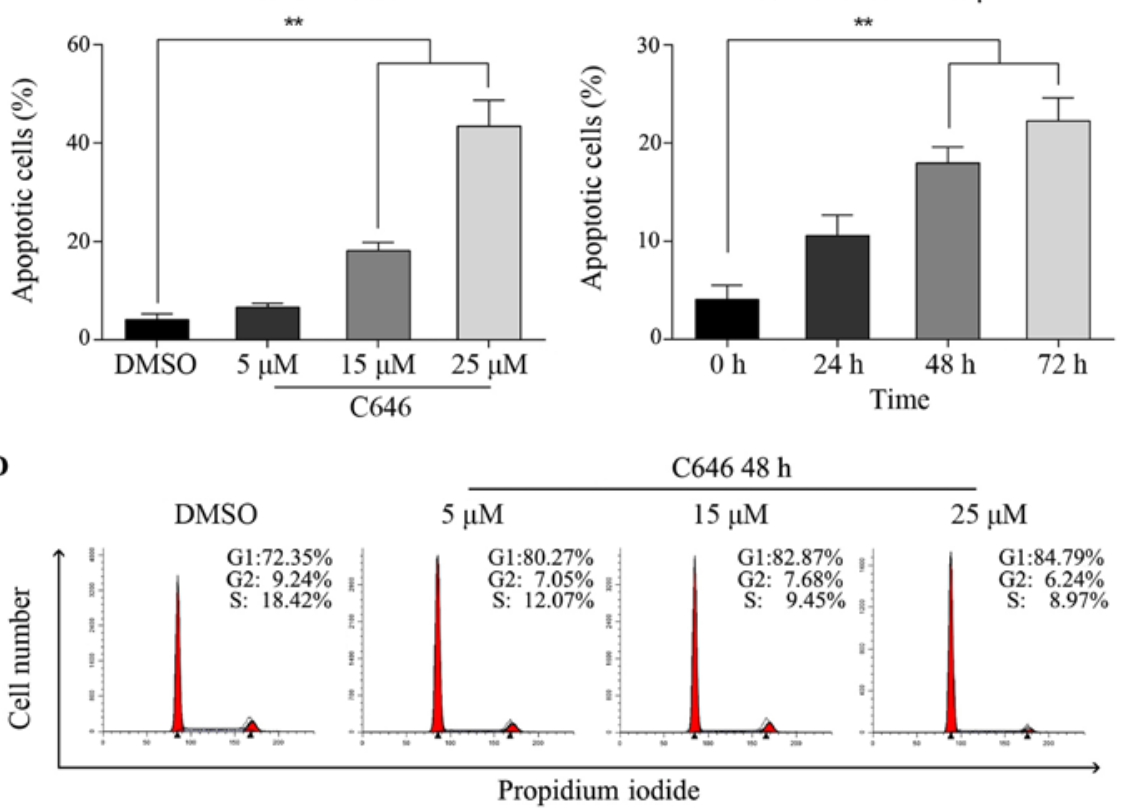

$\mathbf{E}$ GIST82 C646 $48 \mathrm{~h}$
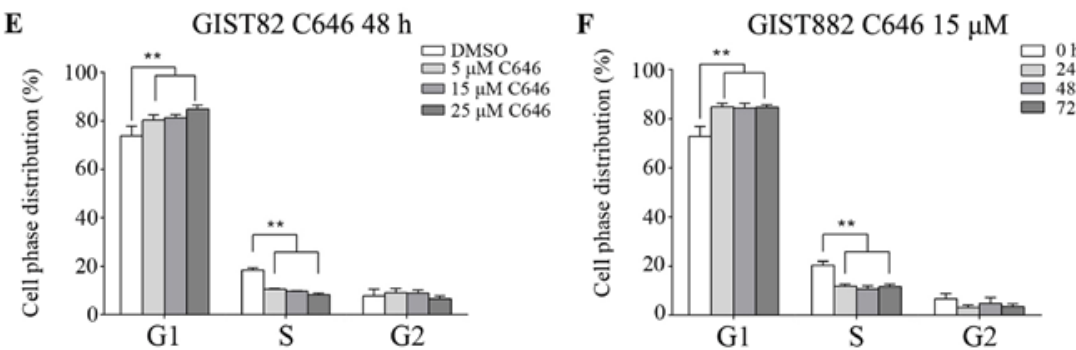

Figure 4. C646 induces apoptosis and cell cycle arrest in GIST cells. GIST882 cells were exposed to C646 (5-25 $\mu$ mol/1) for 24 to $72 \mathrm{~h}$, respectively. DMSO was used as the vehicle control. (A-C) Apoptosis induced by C646 was assessed by Annexin V-FITC/PI staining and was further analysed by flow cytometry $\left({ }^{* *} \mathrm{P}<0.01\right.$ vs. DMSO group or the group treated with $15 \mu \mathrm{mol} / 1 \mathrm{C} 646$ at $0 \mathrm{~h}$ ). (D-F) Cell cycle analysis was performed by flow cytometry to detect cell cycle arrest induced by $\mathrm{C} 646$ following PI staining ( ${ }^{* *} \mathrm{P}<0.01 \mathrm{vs}$. DMSO group or the group treated with $15 \mu \mathrm{mol} / 1 \mathrm{C} 646$ at $0 \mathrm{~h}$ ). GIST, gastrointestinal stromal tumor; DMSO, dimethyl sulfoxide; FITC, fluorescein isothiocyanate; PI, propidium iodide.

suggesting a tumor-suppressor role of $\mathrm{CBP} / \mathrm{p} 300$ in carcinogenesis $(32,33)$. Thus, the function of $\mathrm{CBP} / \mathrm{p} 300$ varies accordingly under different circumstances. The present study demonstrated that blockage of $C B P$ and $p 300$ by specific siRNAs induced cell growth suppression in GITS882 cells. Interestingly, whereas transcriptional inhibition of $C B P$ exhibited a strong antiproliferative activity, p300 inhibition did not exert a similar inhibitory effect on cell proliferation, implying that CBP rather than p300 played a dominant role in the regulation of cell proliferation. These results support the idea that despite their high degree of homology, CBP and p300 may have non-overlapping functions and accordingly may play different roles (34). Nonetheless, silencing of $C B P$ and $p 300$ significantly enhanced caspase-3/7 activity, indicating that apoptosis induction did not completely parallel growth inhibition. Our results revealed that depletion of $\mathrm{CBP} / \mathrm{p} 300$ resulted in decreased ETV1 expression levels along with KIT inactivation in GIST882 cells. Previous studies have reported that CBP/p300 directly interacted with ETV1 and enhanced its DNA-binding and transactivation through acetylation (20). Additionally, upregulated ETV1 expression was detected in ICC, which are precursors of GISTs (35). Therefore, CBP/p300 may represent a specific target for GISTs due to its role in regulating ETV1, the key transcriptional factor that is highly expressed in both GISTs and its precursor cells. These findings prompt us to hypothesize that $\mathrm{CBP} / \mathrm{p} 300$ may stabilize ETV1 via direct acetylation and activate KIT-dependent pathways, contributing to cell proliferation and survival in GISTs. 


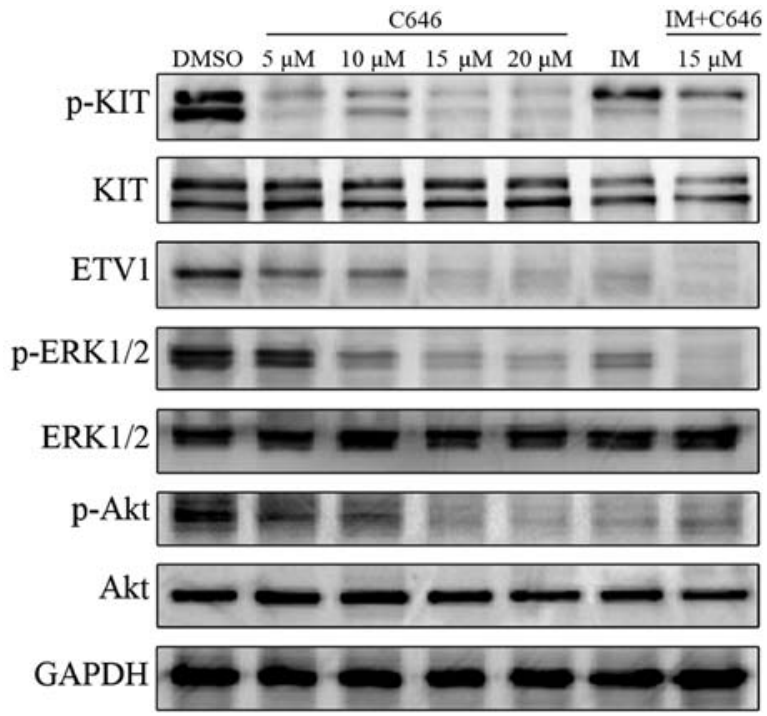

Figure 5. C646 attenuates ETV1 expression and inactivates KIT-dependent pathways. GIST882 cells were treated with C646 (5-20 $\mu \mathrm{mol} / 1)$ for $24 \mathrm{~h}$. Imatinib (500 nmol/l) alone or in combination with C646 (15 $\mu \mathrm{mol} / \mathrm{l})$ was used for the combination study. DMSO was used as the vehicle control. The expression levels of ETV1 and KIT-dependent pathway-related proteins were analysed by western blotting. GAPDH was used as a reference. ETV1, ETS translocation variant 1; GIST, gastrointestinal stromal tumor DMSO, dimethyl sulfoxide; GAPDH, glyceraldehyde 3-phosphate dehydrogenase.

The data reported herein indicate that CBP plays a key role in the regulation of ERK1/2 and JNK activities, whereas p300 does not act in a similar way. It is widely acknowledged that ERK1/2, a subtype of mitogen-activated protein kinases (MAPKs), regulates cell proliferation, differentiation and migration through KIT-dependent pathways (36). JNK, another subtype of MAPKs that is expressed but not phosphorylated in GISTs in vitro (37), participates in the death receptor signaling pathway required for apoptosis induction in various cancers (38-40). Therefore, CBP is required for tumor growth through ERK1/2 phosphorylation and apoptosis regulation via inactivation of JNK in GIST882 cells, whereas p300 does not appear to contribute to these activities. However, both CBP and p300 silencing led to the upregulation of proapoptotic Bax and the downregulation of anti-apoptotic Bcl-2 and Bcl-xL, members of the Bcl-2 family that are involved in the mitochondrial cell death pathway (41), suggesting that $\mathrm{CBP} / \mathrm{p} 300$ affect apoptosis through the regulation of Bcl-2 family proteins. Thus, CBP may regulate apoptosis via both the death receptor signaling pathway and the mitochondrial cell death pathway in GIST cells. In contrast, p300 affects apoptotic cell death through the mitochondrial cell death pathway and has little effect on the death receptor signaling pathway.

To date, a variety of histone deacetylase (HDAC) inhibitors have been shown to induce apoptosis in tumor cells and have been introduced into clinical trials (42). Although pharmacological inhibition of deacetylation by HDAC inhibitors can exert antiproliferative and proapoptotic effects on several GIST cell lines (43), not much is known regarding acetyltransferase inhibitors. To this end, the present study is the first to show strong antiproliferative and proapoptotic effects in imatinib-sensitive GIST cells by C646, a competitive inhibitor of HATs. The GIST882 cells appear to be highly sensitive to the HAT inhibitor based on the observation that GIST cell proliferation is reduced substantially following exposure to C646. Treatment with C646 resulted in marked apoptotic cell death, demonstrating potent antineoplastic activity. In addition to proapoptotic activity, C646 treatment also induced considerable cell cycle arrest at an early time-point $(24 \mathrm{~h})$, showing the high efficacy of its antigrowth effect. Moreover, C646 administration inhibited KIT phosphorylation and deactivated ERK1/2, disrupting the downstream cascade for tumor proliferation and survival. Overall, C646-induced antineoplastic effects follow a similar pattern as that of CBP downregulation. Therefore, it is conceivable that C646 is able to exert these antitumor effects mainly through inhibition of CBP activity. Our data further showed that imatinib and C646 combination therapy would exert synergistic inhibitory effects on GIST cells, suggesting a potential usage of C646 in GIST therapy especially for imatinib-resistant cases. This effect may be partly attributed to the inactivation of KIT and ERK1/2. Additionally, C646 exhibits a strong inhibitory effect on the phosphorylation of Akt, another downstream component of KIT and a critical molecule in GIST tumorigenesis (44). Taken together, our study indicates that C646 may be a promising antineoplastic reagent for GIST therapy.

However, this study has some limitations. Further investigations of the expression and function of $\mathrm{CBP} / \mathrm{p} 300$ in clinical GIST samples or animal models are required to clarify its role in tumorigenesis and progression in vivo. Moreover, although an immediate synergism with imatinib was acquired following C646 administration in GIST882 cells, these effects require further examination in other GIST cell lines that are sensitive and resistant to imatinib. The efficacy and safety of C646 as an antineoplastic agent for GISTs have not yet been fully characterized and remain to be validated both in vitro and in vivo.

In conclusion, our results demonstrate that $C B P$ silencing will inhibit cell proliferation and promote apoptosis induction, whereas $p 300$ inhibition has little effect on cell growth, posing some advantages of CBP as a more effective target for GIST therapy. The molecular mechanisms underlying this antineoplastic effect may be attributed to ETV1 downregulation and inactivation of KIT-dependent pathways. CBP regulates apoptosis through both the death receptor pathway and the mitochondrial cell death pathway in GIST882 cells, whereas p300 has little effect on the death receptor pathway. Furthermore, the HAT inhibitor C646 attenuates ETV1 expression and inactivates KIT-dependent pathways, triggering antiproliferative effects in GIST cells and inducing apoptosis or cell cycle arrest. Consequently, the present study provides mechanistic insight and supports the notion that $\mathrm{CBP} / \mathrm{p} 300$ inactivation by HAT inhibitors may serve as a prospective approach for antitumor therapeutics against GISTs.

\section{Acknowledgements}

This study was supported by the Scientific Research Foundation of the National Health and Family Planning Commission of the People's Republic of China (WKJ-ZJ-1614). We are very grateful to the State Key Laboratory for Diagnosis and Treatment of Infectious Diseases of the First Affiliated Hospital of Zhejiang University and the Department of Oncology of Hangzhou First People's Hospital for providing excellent technical assistance. 


\section{References}

1. Rubin BP, Heinrich MC and Corless CL: Gastrointestinal stromal tumour. Lancet 369: 1731-1741, 2007.

2. Hirota S, Isozaki K, Moriyama Y, Hashimoto K, Nishida T, Ishiguro S, Kawano K, Hanada M, Kurata A, Takeda M, et al: Gain-of-function mutations of c-kit in human gastrointestinal stromal tumors. Science 279: 577-580, 1998.

3. Heinrich MC, Corless CL, Duensing A, McGreevey L, Chen CJ, Joseph N, Singer S, Griffith DJ, Haley A, Town A, et al: PDGFRA activating mutations in gastrointestinal stromal tumors. Science 299: 708-710, 2003.

4. Corless CL, Barnett CM and Heinrich MC: Gastrointestinal stromal tumours: origin and molecular oncology. Nat Rev Cancer 11: 865-878, 2011.

5. D'Amato G, Steinert DM, McAuliffe JC and Trent JC: Update on the biology and therapy of gastrointestinal stromal tumors. Cancer Control 12: 44-56, 2005.

6. Joensuu H, Hohenberger P and Corless CL: Gastrointestinal stromal tumour. Lancet 382: 973-983, 2013.

7. Joensuu H and DeMatteo RP: The management of gastrointestinal stromal tumors: a model for targeted and multidisciplinary therapy of malignancy. Annu Rev Med 63: 247-258, 2012.

8. Heinrich MC, Corless CL, Blanke CD, Demetri GD, Joensuu H, Roberts PJ, Eisenberg BL, von Mehren M, Fletcher CD Sandau K, et al: Molecular correlates of imatinib resistance in gastrointestinal stromal tumors. J Clin Oncol 24: 4764-4774, 2006.

9. Lim KH, Huang MJ, Chen LT, Wang TE, Liu CL, Chang CS Liu MC, Hsieh RK and Tzen CY: Molecular analysis of secondary kinase mutations in imatinib-resistant gastrointestinal stromal tumors. Med Oncol 25: 207-213, 2008.

10. Hou XW, Bai CG, Liu XH, Qiu C, Huang L, Xu JJ and Ma DL: Expression of stem cell factor in gastrointestinal stromal tumors: implications for proliferation and imatinib resistance. Oncol Lett 5: 552-558, 2013.

11. Rutkowski P, Symonides M, Zdzienicki M and Siedlecki JA Developments in targeted therapy of advanced gastrointestinal stromal tumors. Recent Patents Anticancer Drug Discov 3 : 88-99, 2008

12. Kalkhoven E: CBP and p300: HATs for different occasions Biochem Pharmacol 68: 1145-1155, 2004

13. Giordano A and Avantaggiati ML: p300 and CBP: partners for life and death. J Cell Physiol 181: 218-230, 1999.

14. Goodman RH and Smolik S: CBP/p300 in cell growth, transformation, and development. Genes Dev 14: 1553-1577, 2000.

15. Santer FR, Höschele PP, Oh SJ, Erb HH, Bouchal J, Cavarretta IT, Parson W, Meyers DJ, Cole PA and Culig Z: Inhibition of the acetyltransferases p300 and CBP reveals a targetable function for p300 in the survival and invasion pathways of prostate cancer cell lines. Mol Cancer Ther 10: 1644-1655, 2011.

16. Bandyopadhyay D, Okan NA, Bales E, Nascimento L, Cole PA and Medrano EE: Down-regulation of p300/CBP histone acetyltransferase activates a senescence checkpoint in human melanocytes. Cancer Res 62: 6231-6239, 2002.

17. Gao XN, Lin J, Ning QY, Gao L, Yao YS, Zhou JH, Li YH, Wang LL and Yu L: A histone acetyltransferase p300 inhibitor C646 induces cell cycle arrest and apoptosis selectively in AML1-ETO-positive AML cells. PLoS One 8: e55481, 2013

18. Papoutsopoulou S and Janknecht R: Phosphorylation of ETS transcription factor ER81 in a complex with its coactivators CREB-binding protein and p300. Mol Cell Biol 20: 7300-7310, 2000.

19. Baena E, Shao Z, Linn DE, Glass K, Hamblen MJ, Fujiwara Y, Kim J, Nguyen M, Zhang X, Godinho FJ, et al: ETV1 directs androgen metabolism and confers aggressive prostate cancer in targeted mice and patients. Genes Dev 27: 683-698, 2013.

20. Goel A and Janknecht R: Acetylation-mediated transcriptional activation of the ETS protein ER81 by p300, P/CAF, and HER2/Neu Mol Cell Biol 23: 6243-6254, 2003 .

21. Chi P, Chen Y,Zhang L, Guo X, Wongvipat J, Shamu T, Fletcher JA Dewell S, Maki RG, Zheng D, et al: ETV1 is a lineage survival factor that cooperates with KIT in gastrointestinal stromal tumours. Nature 467: 849-853, 2010.

22. Zhang Y, Gu ML, Zhou XX, Ma H, Yao HP and Ji F: Altered expression of ETV1 and its contribution to tumorigenic phenotypes in gastrointestinal stromal tumors. Oncol Rep 32: 927-934, 2014

23. Bowers EM, Yan G, Mukherjee C, Orry A, Wang L, Holbert MA Crump NT, Hazzalin CA, Liszczak G, Yuan H, et al: Virtual ligand screening of the p300/CBP histone acetyltransferase: identification of a selective small molecule inhibitor. Chem Biol 17: 471-482, 2010.
24. Cohen MH, Farrell A, Justice R and Pazdur R: Approval summary: imatinib mesylate in the treatment of metastatic and/or unresectable malignant gastrointestinal stromal tumors. Oncologist 14: 174-180, 2009.

25. Judson I and Demetri G: Advances in the treatment of gastrointestinal stromal tumours. Ann Oncol 18 (Suppl 10): x20-x24, 2007.

26. Demetri GD, van Oosterom AT, Garrett CR, Blackstein ME Shah MH, Verweij J, McArthur G, Judson IR, Heinrich MC, Morgan JA, et al: Efficacy and safety of sunitinib in patients with advanced gastrointestinal stromal tumour after failure of imatinib: a randomised controlled trial. Lancet 368: 1329-1338, 2006.

27. Lee JH, Kim Y, Choi JW and Kim YS: Correlation of imatinib resistance with the mutational status of KIT and PDGFRA genes in gastrointestinal stromal tumors: a meta-analysis. J Gastrointestin Liver Dis 22: 413-418, 2013.

28. Tarn C, Rink L, Merkel E, Flieder D, Pathak H, Koumbi D, Testa JR, Eisenberg B, von Mehren M and Godwin AK Insulin-like growth factor 1 receptor is a potential therapeutic target for gastrointestinal stromal tumors. Proc Natl Acad Sci USA 105: 8387-8392, 2008

29. Koelz M, Lense J, Wrba F, Scheffler M, Dienes HP and Odenthal M: Down-regulation of miR-221 and miR-222 correlates with pronounced Kit expression in gastrointestinal stromal tumors. Int J Oncol 38: 503-511, 2011.

30. Ionov Y, Matsui S and Cowell JK: A role for p300/CREB binding protein genes in promoting cancer progression in colon cancer cell lines with microsatellite instability. Proc Natl Acad Sci USA 101: 1273-1278, 2004

31. Ianculescu I, Wu DY, Siegmund KD and Stallcup MR: Selective roles for cAMP response element-binding protein binding protein and $\mathrm{p} 300$ protein as coregulators for androgen-regulated gene expression in advanced prostate cancer cells. J Biol Chem 287: 4000-4013, 2012

32. Bayly R, Chuen L, Currie RA, Hyndman BD, Casselman R, Blobel GA and LeBrun DP: E2A-PBX1 interacts directly with the KIX domain of $\mathrm{CBP} / \mathrm{p} 300$ in the induction of proliferation in primary hematopoietic cells. J Biol Chem 279: 55362-55371, 2004.

33. Kung AL, Rebel VI, Bronson RT, Ch'ng LE, Sieff CA, Livingston DM and Yao TP: Gene dose-dependent control of hematopoiesis and hematologic tumor suppression by CBP. Genes Dev 14: 272-277, 2000

34. Kawasaki H, Eckner R, Yao TP, Taira K, Chiu R, Livingston DM and Yokoyama KK: Distinct roles of the co-activators p300 and CBP in retinoic-acid-induced F9-cell differentiation. Nature 393: 284-289, 1998

35. Rubin BP: Bioinformatic mining of gene expression datasets identifies ETV1 as a critical regulator of oncogenesis in gastrointestinal stromal tumors. Cancer Cell 18: 407-408, 2010.

36. Dhillon AS, Hagan S, Rath O and Kolch W: MAP kinase signalling pathways in cancer. Oncogene 26: 3279-3290, 2007.

37. Duensing A, Medeiros F, McConarty B, Joseph NE, Panigrahy D, Singer S, Fletcher CD, Demetri GD and Fletcher JA: Mechanisms of oncogenic KIT signal transduction in primary gastrointestinal stromal tumors (GISTs). Oncogene 23: 3999-4006, 2004.

38. Wang D, Lu J, Liu Y, Meng Q, Xie J, Wang Z and Teng L: Liquiritigenin induces tumor cell death through mitogen-activated protein kinase- (MPAKs-) mediated pathway in hepatocellular carcinoma cells. Biomed Res Int 2014: 965316, 2014.

39. Yoon JY, Cho HS, Lee JJ, Lee HJ, Jun SY, Lee JH, Song HH, Choi S, Saloura V, Park CG, et al: Novel TRAIL sensitizer Taraxacum officinale F.H. Wigg enhances TRAIL-induced apoptosis in Huh7 cells. Mol Carcinog 55: 387-396, 2016.

40. Kuo KL, Ho IL, Shi CS, Wu JT, Lin WC, Tsai YC, Chang HC, Chou CT, Hsu CH, Hsieh JT, et al: MLN4924, a novel protein neddylation inhibitor, suppresses proliferation and migration of human urothelial carcinoma: in vitro and in vivo studies. Cancer Lett 363: 127-136, 2015.

41. Krestnikova N, Stulpinas A, Imbrasaite A, Sinkeviciute G and Kalvelyte AV: JNK implication in adipocyte-like cell death induced by chemotherapeutic drug cisplatin. J Toxicol Sci 40: 21-32, 2015

42. Bolden JE, Peart MJ and Johnstone RW: Anticancer activities of histone deacetylase inhibitors. Nat Rev Drug Discov 5: 769-784, 2006.

43. Mühlenberg T, Zhang Y, Wagner AJ, Grabellus F, Bradner J, Taeger G, Lang H, Taguchi T, Schuler M, Fletcher JA, et al: Inhibitors of deacetylases suppress oncogenic KIT signaling, acetylate HSP90, and induce apoptosis in gastrointestinal stromal tumors. Cancer Res 69: 6941-6950, 2009.

44. Patel S: Exploring novel therapeutic targets in GIST: focus on the PI3K/Akt/mTOR pathway. Curr Oncol Rep 15: 386-395, 2013. 